LISANUL ARAB 10 (1) (2021)
(Terakreditasi Sinta 4)
http://journal.unnes.ac.id/sju/index.php/laa

\title{
KATA TANYA (ISTIFHÂM) DALAM AL-QUR'AN JUZ 20 (ANALISIS SEMANTIK)
}

\author{
Ni’matul Lisana $^{\bowtie}$, Hasan Busri ${ }^{\bowtie}$, Retno Purnama Irawati ${ }^{\bowtie}$
}

Jurusan Bahasa Asing, Fakultas Bahasa dan Seni, Universitas Negeri Semarang

\begin{tabular}{|c|c|}
\hline Info Artikel & Abstrak \\
\hline $\begin{array}{l}\text { Sejarah Artikel: } \\
\text { Diterima Januari } 2021 \\
\text { Disetujui Maret } 2021 \\
\text { Dipublikasikan April } \\
2021\end{array}$ & $\begin{array}{l}\text { Al Qur'an selain sebagai pedoman pokok dalam beragama sejak dahulu telah menjadi sumber data } \\
\text { primer dalam berbagai penelitian dan studi karena kekayaan konsep keilmuan yang ada di } \\
\text { dalamnya. Istifhâm sebagai salah satu ragam kalimat yang digunakan sebagai media interaksi dalam } \\
\text { Al-Qur'an. Dalam penelitian ini peneliti membahas istifhâm pada Al-Qur'an juz ke 20. Penelitian } \\
\text { ini merupakan penelitian kualitatif dengan desain penelitian library research. Tujuan penelitian ini } \\
\text { adalah untuk mendeskripsikan jenis-jenis dan fungsi kata tanya (istifhâm) yang terdapat dalam Al- }\end{array}$ \\
\hline $\begin{array}{l}\text { Keywords: } \\
\text { Qur'an; Istifhâm; Syntactic } \\
\text { Analysis }\end{array}$ & $\begin{array}{l}\text { Qur'an juz 20. Pengumpulan data dilakukan menggunakan teknik sampling pertimbangan } \\
\text { (purposive sampling). Instrumen penelitian berupa kartu data dan lembar rekapitulasi. Teknik } \\
\text { analisis data menggunakan metode analisis isi. Hasil penelitian ini menunjukkan bahwa peneliti } \\
\text { menemukan } 32 \text { data yang berupa adawatul istifhâm antara lain hamzah, man, hal, maa, aina, kaifa, } \\
\text { maadzaa, am, dan ayyana yang terdiri atas } 26 \text { istifhâm majazi dan } 8 \text { data istifhâm haqiqi yang } \\
\text { dibedakan menjadi } 9 \text { fungsi dan tujuan istifhâm. }\end{array}$ \\
\hline
\end{tabular}

\begin{abstract}
The Qur'an, apart from being a basic guideline in religion, has long been a primary data source in various studies and studies because of the richness of scientific concepts contained in it. Istifham as one of the various sentences used as a medium of interaction in the Al-Qur'an. In this study, the researcher discusses the istifham in the 20th Al-Qur'an juz. This research is a qualitative research with a research library research design. The purpose of this study was to describe the types and functions of the interrogative words (istifhâm) contained in Al-Qur'an juz 20. The data was collected using purposive sampling technique. The research instruments were data cards and recapitulation sheets. The data analysis technique used the content analysis method. The results of this study indicate that the researchers found 32 data in the form of adawatul istifhâm, including hamzah, man, hal, maa, aina, kaifa, maadzaa, am, and ayyana consisting of 26 istifhâm majazi and 8 istifhâm haqiqi data which are divided into 9 functions and istifhâm goals.
\end{abstract}

\begin{tabular}{ll}
\hline Alamat korespondensi: & P- ISSN 2252-6269 \\
Gedung B4 Lantai 1 FBS Unnes & E- ISSN 2721-4222 \\
Kampus Sekaran, Gunungpati, Semarang, 50229 & \\
E-mail: nikmatulisana29@gmail.com; hasanbusri@mail.unnes.ac.id; rp.irawati@mail.unnes.ac.id &
\end{tabular}




\section{PENDAHULUAN}

Al Qur'an selain sebagai pedoman pokok dalam beragama sejak dahulu telah menjadi sumber data primer dalam berbagai penelitian dalam berbagai studi karena kekayaan konsep keilmuan yang ada di dalamnya. Dalam melakukan interaksi, Al-Qurân menggunakan beragam kalimat, antara lain; kalimat pernyataan (jumlah khabariyah), kalimat perintah (amr), kalimat larangan (nahi), kalimat pertanyaan (istifhâm), dan lain sebagainya (Ma'sum 2007: 3).

Salah satu kalimat yang digunakan dalam Al-qur'an adalah kalimat pertanyaan (istifhâm). Istifhâm adalah kalimat yang digunakan untuk mencari pengetahuan tentang sesuatu yang sebelumnya tidak diketahui (Amin dalam Ashar 2016: 3). Jika orang ingin mengetahui jawaban terhadap suatu masalah atau keadaan, maka ia menanyakannya, dan kalimat yang dipakai adalah kalimat tanya.

Istifhâm merupakan istilah dalam bahasa Arab yang secara etimologi merupakan bentuk masdar dari kata istafhama yang berarti istaudhaha (Fawwal 1992: 87). Kata istifhâm dibentuk dari akar kata fahima mendapat tambahan alif, sin, ta' di awal kata yang salah satu fungsinya adalah meminta. Dengan demikian istifhâm berarti meminta penjelasan, permintaan keterangan, kata tanya, atau menuntut keterangan (thalab al-fahm) (Al-Suyuti n.d.: 79).

Dalam kajian bahasa Arab, istifhâm diklasifikasikan menjadi dua pola, yang pertama istifhâm haqiqi dan yang kedua adalah istifhâm majazi. Istifhâm haqiqi bermakna pertanyaan seseorang kepada orang lain tentang sesuatu yang memang benar-benar belum diketahui sebelumnya. Adapun istifhâm majazi adalah pertanyaan tentang sesuatu yang sebenarnya sudah diketahui sebelumnya.

Pengertian istifhâm dari sudut pandang semantik yang merupakan cabang linguistik yang meneliti makna, di dalamnya mengkaji makna kata memahami kajian kata tersebut yang berkenaan dengan hubungan-hubungan makna yang membuat kata tersebut berbeda dari katakata lain. Arti dalam hal ini menyangkut makna leksikal dari kata-kata itu sendiri yang cenderung terdapat di dalam kamus, sebagai leksem (Djajasudarma 1999: 1).

Dalam kondisi ini, fungsi yang dimiliki oleh kalimat istifhâm tersebut tidak lagi orisinil sebagai pertanyaan yang mengharapkan jawaban, namun beralih kepada fungsi-fungsi lainnya semisal larangan, perintah, pengingkaran, doa, harapan, sangkalan, serta tujuan lainnya (Nurdiyanto 2016: 40-41).

Peneliti melakukan penelitian tentang Istifhâm (Kata Tanya) dalam Al-Qur'an Juz 20 berdasarkan dua alasan: pertama, karena kurangnya peminat yang ingin menganalisis adawatul istifhâm dalam juz 20, khususnya di Pendidikan Bahasa Arab UNNES. Hal ini dibuktikan dengan data peneliti yang menemukan baru satu peneliti yang meneliti tentang judul istifhâm ini.

Kedua, jumlah adawatul Istifhâm dalam Juz 20 tersebut sangat beragam bentuk dan maknanya sehingga cukup penting untuk dipelajari bagi para pembelajar bahasa Arab, karena para pelajar bahasa Arab tidak akan bisa lepas dari adawatul istifhâm dan diharapkan mampu menarik minat pembaca untuk mengkaji kalimat istifhâm di dalam Al-Qur'an.

Alasan di atas, mendorong peneliti untuk melakukan penelitian dengan judul "Kata Tanya (Istifhâm) dalam Al-Qur'an Juz 20 (Analisis Semantik)".

\section{LANDASAN TEORI \\ Istifhâm dalam Bahasa Arab}

Kata istifhâm secara bahasa berasal dari kata kerja tsulatsi maziid (ثلاثى مزيد) dari (إستفهو-يستفهم-إستفهاما) dengan wazan (استفعل-يستفعل_استفعالا) yang bermakna mencari pemahaman atau pengertian (Ghalayaini 1984: 45). istifhâm sebagai salah satu kalam insyâ' thalabi secara etimologi merupakan mashdar dari kata istafhama yang berarti istaudhaha.

Sedangkan pengertian istifhâm secara terminologi (Ma'sum 2007: 23-24) adalah mencari pemahaman tentang sesuatu hal yang tidak diketahui. Istifhâm adalah mencari pemahaman tentang hakikat, nama, jumlah, 
serta sifat dari suatu hal. Sedangkan menurut Ali Jarim dan Musthofa Amin (Al-Jarim dan Amin 1964: 194) istifhâm didefinisikan dengan mancari pengetahuan tentang sesuatu yang sebelumnya tidak diketahui.

Dengan demikian pengertian istifhâm adalah bentuk kalimat yang dipergunakan untuk mendapatkan informasi yang jelas tentang suatu masalah yang belum diketahui sebelumnya. Istifhâm (pertanyaan) dapat dilihat dari sudut pandang sintaksis, semantis, dan juga pragmatis.

Kata tanya dalam bahasa Arab selalu ditempatkan di awal kalimat, sedangkan posisi kata tanya dalam bahasa Indonesia bisa di awal, tengah, atau akhir kalimat (Nikmah 2020: 189). Kata tanya dalam bahasa Arab adalah: hamzah (apakah), hal (apakah), mâ (apa), man (siapa), kaifa (bagaimana), matâ (kapan), ayyâna (bilamana), annâ (darimana), kam (berapa), aina (dimana) dan ayyu (apa/siapa).

\section{Klasifikasi Istifhâm}

Dalam kajian bahasa Arab, istifhâm terbagi menjadi dua bagian yaitu istifhâm haqiqi dan istifhâm majazi (Al-Jarim dan Amin 1964: 198). Istifhâm haqiqi adalah pola istifhâm yang dilontarkan kepada seseorang untuk mengetahui sesuatu yang belum diketahui. Istifhâm majazi adalah pola istifhâm yang sudah diketahui kebenarnya. Fungsi dari istifam majazi sudah tidak haqiqi (sifat aslinya) melainkan mengharapakan jawaban yang beralih pada fungsi-fungsi lainnya seperti, doa, harapan, perintah, larangan, celaan, pengingkaran dan lainnya.

\section{Macam-macam Perangkat Istifhâm (Adawatul Istifhâm)}

Perangkat-perangkat istifhâm (Adawatul Istifhâm) yang biasa digunakan dalam kaidah bahasa Arab, antara lain:

\section{1) $\operatorname{Hamzah}$ (أ)}

Huruf hamzah sebagai sebuah perangkat istifhâm memiliki dua fungsi asli (Al-Jarim dan Amin 1964: 194): a) Tasawwur, dalam hal ini hamzah langsung diiringi dengan hal yang ditanyakan dan mempunyai bandingan dengan kata yang disebutkan setelah lafadz am yang bearti "atau".

b) Tashdiq, maksudnya berupa pembenaran terhadap hal yang ditanyakan dan tidak menyebutkan bandingan perkara yang ditanyakan.

\section{2) Man si}

Kata ini berfungsi untuk menyatakan makhluk yang berakal yang diletakkan diawal kalimat juga terletak sebelum isim. Posisi kata tanya نsebagai subjek (mubtada'). Misal:

\section{3) Hal sل}

Penggunaan huruf hal dalam kalimat istifhâm hanya berfungsi sebagai tashdiq saja, yang tujuannya untuk mengetahui terjadi atau tidaknya sesuatu.

4) $M a$ L

Kata tanya ini berfungsi menyakan sesuatu yang tidak berakal, yang terletak sebelum fi'il.

\section{5) Mata (متى)}

Dalam kaidah bahasa Arab, kata ini berfungsi untuk menyakan keterangan waktu, baik yang lalu maupun yang akan datang yang berposisi sebagai dhorof.

\section{6) Ayyana أبان}

Kata tanya ini biasanya terletak sebelum kata benda dan kata kerja. Fungsi kata tanya tersebut menerangkan masa yang secara spesifik bersejarah. 
7) أين Ayna

Kata tanya ini berfungsi menanyakan keterangan tempat yang posisinya sebelum kata kerja dan kata benda.

\section{8) Kaifa ( كيف)}

Dalam kaidah istifhâm terletak sebelum kata kerja dan kata benda, yang berfungsi untuk menerangkan keadaan.

\section{9) $\operatorname{Kam}(ك)$}

Dalam tata bahasa kalimat tanya tersebut berfungsi untuk mengetahui jumlah.

10) Ayyu أي

Kata ini berfungsi untuk menanyakan dan menghendaki perbedaan antara dua hal yang terletak setelah kata benda yang menempati berbagi posisi mubtada', khobar, maful bih.

\section{1) Anna أنّى}

Kata tanya ini memiliki ciri khas tersendiri, yakni terletak sebelum huruf jar yang memiliki beberapa makna sesuai dialognya seperti: Bagaimana, dari mana dan kapan.

\section{Pola Kalimat Istifhâm dalam Al-Qur'an dan Fungsinya}

Terkait dengan pola istifhâm terlepas dari fungsi asalnya yang memiliki makna istifhâm beraneka ragam serta berbeda dengan fungsi dasarnya, maka sisi dinamika kebahasaan kalimat istifhâm mulai bermunculan. Adapun beberapa fungsi kalimat istifhâm majazi yang sering digunakan dalam ayat al-Qur'an, antara lain:

1) Taqrir (menetapkan), dalam hal ini pola kalimat istifhâm tidak memerlukan terhadap jawaban, sebab tujuannya adalah menetapkan suatu gagasan bukan pertanyaan. Pola yang sering digunakan hamzah yang kemudian diikuti oleh fi'il nafi.

2) Ikhbar (Menginformasikan), berfungsi menerangkan informasi tentang sesuatu dan bertujuan untuk menguatkan informasi atau kabar yang disampaikan dalam suatu kalimat.
3) Al-Taswiyah (menyamakan), pola istifhâm ini bertujuan menyamakan dan menunjukkan kalimat dan sesudah huruf istifhâm memiliki kedudukan yang sama. Perangkat yang digunakan hamzah dan hal.

4) Al-Irsyad (Petunjuk) dan Al-Tadzkir (pengingat), kedua uslub istifhâm dalam pola ini bertujuan sebagai petunjuk dan pengingat. Digunakan untuk evaluasi diri sendiri, sebagai bahan intropeksi diri untuk tidak melakukan hal yang sama di lain waktu.

5) Ifham (Pemberian pemahaman), istifhâm berfungsi untuk memberikan pemahaman yang memiliki korelasi dengan ayat sesudahnya.

6) Tashwiq (memotivasi), bertujuan untuk menggiring perasaan manusia kepada gagasan yang dimunculkan dalam kalimat istifhâm tersebut.

7) Al-Amr (Perintah), penggunaan kalimat perintah disini memiliki pola sisi sendiri yang menggunakan struktur istifhâm didahului dengan penjelasan-pejelasan terlebih dahulu lebih detail, kemudian dikuatkan dengan pola $a m r$.

8) Nafi (meniadakan)

9) Tamanna (Pengharapan)

10) Nahi (Larangan), situasi ini istifhâm berfungsi untuk menegaskan tentang pelarangan terhadap sesuatu.

11) Taubikh (celaan), pola istifhâm ini bertujuan untuk mencela

12) Ta'zhim (mengagungkan), istifhâm juga berfungsi untuk mengagung-agungkan sesuatu,

13) Tahqir, menghina/ merendahkan),model istifhâm disini bertujuan untuk menghina atau merendahkan derajat,

14) Ta’ajub (mengagumi/ keheranan)

Pada dasarnya, masih banyak sekali makna pola kalimat istifhâm yang belum dipaparkan, karena banyaknya ragam karya makna dan sisi yang dikandung. Sebab pola istifhâm adalah pola kalimat dimana pemahamanan terhadap makna suatu kalimat akan selalu berkembang dan sangat bergantung 
kepada konteks dan kondisi ketika kalimat itu berbicara. Namun, dalam pembahasan analisis dalam skripsi ini berfokus pada fungsi-fungsi tersebut dengan maksimal.

\section{Semantik Arab}

Menurut Pateda (Nasution 2017: 148) semantik adalah studi tentang hubungan antara suatu pembeda linguistik dengan hubungan proses mental atau simbol dalam aktivitas bicara. Definisi semantik secara terminologi yang dikemukakan oleh Umar (Nasution 2017: 148) "semantik adalah studi tentang makna, atau ilmu yang mempelajari tentang makna, atau cabang linguistik yang mengkaji tentang teori makna". Dapat diketahaui bahwa semantik merupakan bagian dari kajian linguistik yang menjadikan makna sebagai obyek kajiannya.

Dalam beberapa literatur berbahasa Arab disiplin ilmu ini disebut dengan berbagai istilah, yaitu " bahkan disebut سيمانتكsebagai kata pungutan dari bahasa Inggris (semantics) atau Prancis (semantique) (Nasution 2017: 147). Al-Jurjani (2003: 108) menyatakan pendapat "Semantik adalah suatu keadaan di mana untuk mengetahuinya diperlukan pengetahuan pada sesuatu yang lain, hal yang pertama adalah al-dāl (penanda) dan yang kedua adalah al-madlūl (petanda)".

\section{Teori Semantik Kontekstual (Al-Nazariyyah al-Siyaqiyyah)}

Secara umum, konteks adalah semua aspek yang berhubungan dengan lingkungan fisik dan sosial suatu tuturan. Konteks boleh jadi mengacu pada tuturan sebelum dan sesudah tuturan tersebut, pada situasi yang berhubungan dengan kebiasaan partisipan dan budaya masyarakat pengguna bahasa (Alfarisi 2014:106). Teori yang dikembangkan oleh John Rupert Firth (1890-1960) menolak dengan tegas makna-makna struktur bahasa yang tidak dikemas dalam konteks. Inti dari teori kontekstual adalah mengidentifikasi makna kata perlu menentukan seperangkat konteks yang menyertainya (Kholison 2016: 126).
Jadi, makna kontekstual adalah makna yang timbul dari situasi atau keadaan terjadinya suatu ujaran. Makna pada hakekatnya memang berhubungan erat dengan kata atau susunan kata yang terdapat dalam sebuah kalimat, sehingga sebuah kata dapat dipahami ketika telah dimengerti maksud dari konteks kalimat tersebut. Karena itu, menurut Chaer, memahami makna leksikal dan makna gramatikal saja belum cukup untuk dapat memahami makna suatu ujaran, sebab untuk dapat memahami makna suatu ujaran harus pula diketahui konteks dari terjadinya ujaran itu. Konteks ujaran itu dapat berupa konteks intrakalimat, antarkalimat, bidang ujaran, atau juga situasi ujaran (Chaer 2003: 285-287).

\section{Analisis Makna Berdasarkan Konteks}

Mengkaji kata dan makna dalam konteks Al-Quran adalah hal sangat menarik karena AlQuran mengungkapkan sesuatu kejadian dengan sebagus-bagus ibarat dan setiap kalimat yang digunakan dalam Al-Quran mempunyai makna yang mendalam dan bermacam-macam sesuai konteks yang mengikutinya. Terdapat 320.015 huruf dan 74.439 kata dalam Al-Quran (Shihab 2000: 3-5).

Kedudukan masing-masing kata saling terpisah, tetapi sangat berhubungan satu dengan yang lainya dan hubungan antar kata tersebut akan menghasilkan suatu makna yang konkret. Dengan kata lain, kata-kata itu membentuk kelompok-kelompok yang bervariasi, besar dan kecil, berhubungan satu sama lain dengan berbagai cara, sehingga menghasilkan keteraturan yang menyeluruh, sangat kompleks dan rumit sebagai kerangka kerja gabungan konseptual (Shihab 1994: 4).

Untuk itu dibutuhkan suatu pendekatan untuk mengakaji makna dalam Al-Qur'an, salah satu cabang ilmu bahasa yang digunakan untuk mengkaji makna-makna kata adalah semantik. Dan dalam penelitian ini menganalisis makna yang berdasarkan konteks ayat Al-Qur'an tersebut, seperti mempertimbangkan asbabun nuzul surat tersebut dan menghubungkan ujaran dengan konteks penggunaannya, menjadikan kondisi dimana tuturan itu terjadi. 


\section{Al-Qur'an Juz 20}

Penelitian ini mengambil salah satu objek dalam Al-Qur'an, yaitu juz ke 20 dalam AlQur'an untuk diteliti. Dalam juz 20 tersebut, terdapat tiga surat, yaitu surat An-Naml, surat Al-Qashash, dan surat Al-Ankabut. Juz 20 dimulai dengan surat An-Naml ayat sambungan dari juz sebelumnya, yaitu ayat 56 dan berakhir di surat Al-Ankabut ayat 45. Jumlah ayat dalam juz ini adalah 171 ayat dengan rincian surat AnNaml mulai ayat 60-93, surat Al-Qashash ayat 188, dan surat Al-Ankabut ayat 1-44.

\section{METODE PENELITIAN}

Penelitian ini menggunakan jenis penelitian kualitatif dengan desain penelitian library research yang membatasi kegiatannya hanya pada bahan-bahan koleksi perpustakaan saja tanpa memerlukan riset lapangan (Zed 2004:1-2). Menurut Strauss dan Corbin (Nugrahani 2014: 9), penelitian kualitatif merupakan jenis penelitian yang temuannya tidak diperoleh melalui prosedur statistik atau bentuk hitungan lainnya.

Penelitian kualitatif merujuk pada analisis data non-matematis. Prosedur ini menghasilkan temuan yang diperoleh melalui data-data yang dikumpulkan dengan beragam sarana, antara lain wawancara, pengamatan, dokumen atau arsip, dan tes (Nugrahani 2014: 9). Data yang diperoleh berupa dokumen yang berasal dari AlQur'an juz ke 20. Data yang dicari adalah adawatul istifhâm. Bahan kepustakaan yang dijadikan sumber dalam penelitian ini adalah AlQur'an juz ke 20.

Instrumen penelitian berupa kartu data dan lembar rekapitulasi. Pengumpulan data dilakukan dengan teknik dokumentasi, sedangkan teknik pengambilan data menggunakan teknik sampling pertimbangan (purposive sampling). Instrumen penelitian berupa kartu data dan lembar rekapitulasi. Dan analisis data menggunakan teknik analisis data menganalisis isi.

\section{HASIL DAN PEMBAHASAN}

Peneliti menemukan 32 data kalimat yang memuat adawatul istifham dalam Al-Qur'an juz ke 20, yaitu dalam surat An-Naml, Al-Qasas, dan Al-Ankabut.

\section{Klasifikasi Istifham}

Berdasarkan data yang telah ditemukan, dari 32 ayat yang mengandung kata tanya (istifhâm) dalam Al-Quran juz 20 ditemukan jenis istifhâm majazi sebanyak 26 buah dengan rincian dalam surat 12 buah terletak pada surat AnNaml, dan sebanyak 10 buah terletak pada surat Al-Qassas, sedangkan pada surat Al-Ankabut sebanyak 2 buah. Adapun 8 jenis istifhâm haqiqi yang terdapat pada Al-Quran Juz 20 sebanyak 1 buah terdapat pada surat An-Naml, 5 buah pada surat Al-Qashash dan 2 buah terdapat pada surat Al-Ankabut.

\section{Makna (Fungsi dan Tujuan) Istifham}

Berdasarkan hasil penelitian, dapat diketahui bahwa 24 istifhâm dalam Al-Qur'an juz 20 yang telah ditemukan dapat dibedakan menjadi 9 fungsi dan tujuan yaitu (1) fungsi ikhbar dengan tujuan menginformasikan (2) fungsi Al-Irsyad dan al-tadzkir dengan tujuan memberikan petunjuk dan pengingat (3) ifham dengan tujuan memberikan pemahaman (4) tashwiq dengan tujuan memotivasi (5) nafi' dengan tujuan meniadakan (6) taubikh dengan tujuan mengejek (7) tahqir dengan tujuan menghina/merendahkan (8) ta'ajjub dengan tujuan keheranan dan (9) tashdiq dengan tujuan pembenaran.

Fungsi dan tujuan kata tanya (istifhâm) yang terdapat dalam Al-Qur'an Juz 20 yang telah ditemukan yaitu 9 fungsi dan tujuan kata tanya (istifhâm) dalam Al-Quran Juz 20 tersebar dalam beberapa surat, kata tanya (istifhâm) dengan fungsi dan tujuan ikhbar (menginformasikan) dietmukan pada surat An-Naml ayat 65; AlQashashn ayat 12 dan Al-Ankabut ayat ayat 10. Dengan fungsi dan tujuan istifhâm al-irsyad wa tadzkir (petunjuk dan pengingat) terdapat dalam 
4 ayat yakni surat An-Naml ayat 69; surat AlQashash ayat 47 dan 61; dan Al-Ankabut ayat 4. Istifhâm dengan fungsi dan tujuan ifham (pemberian pemahaman) terdiri dari 4 buah, masing-masing terdapat pada surat An-Naml ayat 86; Al-Qashash ayat 50,60, dan 72. Istifhâm dengan fungsi dan tujuan Tashwiq (memotivasi) hanya terdapat dalam surat Al-Qashash ayat 71. Istifhâm dengan fungsi dan tujuan nafi (meniadakan) juga hanya terdapat dalam satu ayat, yakni surat Al-Naml ayat 90 .

Istifhâm dengan fungsi dan tujuan Taubikh (celaan) terdapat 8 buah terdapat pada surat AnNaml ayat 59, 67, dan 84; Al-Qasas ayat 62, 65, 74, dan 78; dan surat Al-Ankabut ayat 29. Istifhâm dengan fungsi dan tujuan Tahqir (menghina) terdapat 2 buah pada Al-Qashash ayat 19 dan 48. Istifhâm dengan fungsi dan tujuan Ta'ajjub (mengagumi/keheranan) terdiri dari satu buah terdapat pada surat Al-Qashash ayat 23. Istifhâm dengan fungsi dan tujuan Tashdiq (pembenaran) terdiri dari 7 buah, terdapat pada surat An-Naml ayat 60, 61, 62, 63, dan 64; A1Ankabut ayat 57; dan surat Al-Ankabut ayat 2.

\section{SIMPULAN}

Setelah memperoleh hasil penelitian dan melakukan analisis sesuai dengan tujuan penelitian, dihasilkan kesimpulan penelitian sebagai berikut:

Terdapat 2 jenis kata tanya (istifhâm) yang terdapat dalam Al-Qur'an juz 20, yaitu jenis istifhâm majazi sebanyak 26 buah. Sedangkan jenis istifhâm haqiqi yang ditemukan sebanyak 8 buah. Jenis istifhâm majazi yang terdapat pada Al-Quran juz 20 sebanyak 12 buah terletak pada surat An- Naml, dan sebanyak 10 buah terletak pada surat Al-Qassas, sedangkan pada surat A1Ankabut sebanyak 2 buah. Adapun 8 jenis istifhâm haqiqi yang terdapat pada Al-Quran Juz 20 sebanyak 1 buah terdapat pada surat AnNaml, 5 buah pada surat Al-Qashash dan 2 buah terdapat pada surat Al-Ankabut.

Terdapat 9 makna (fungsi dan tujuan) kata tanya (istifhâm) yang terdapat dalam Al-Qur'an juz 20, yaitu (1) fungsi ikhbar dengan tujuan menginformasikan; (2) fungsi Al-Irsyad dan altadzkir dengan tujuan memberikan petunjuk dan pengingat; (3) ifham dengan tujuan memberikan pemahaman; (4) tashwiq dengan tujuan memotivasi; (5) nafi' dengan tujuan meniadakan; (6) taubikh dengan tujuan mengejek; (7) tahqir dengan tujuan menghina/merendahkan; (8) ta'ajjub dengan tujuan keheranan dan (9) tashdiq dengan tujuan pembenaran.

\section{DAFTAR PUSTAKA}

Al-Jarim, Ali, and Musthafa Amin. 1964. Al-Balaghah Al-Wadhihah: AlBayan Wa Al-Ma'ani Wa Al-Badi' Lilmadaris Al-Tsanawiyah. Kairo: Dar al Mal'arif Bimisr.

Al-Suyuti, Jalaluddin Abdurrahman. n.d. Al-Itqan Fi Ulum Al-Qur'an. 2nd ed. Beirut: Dar Al-Fikr.

Alfarisi, Muhammad Zaka. 2014. Pedoman Penerjemahan Arab Indonesia: Strategi Metode Prosedur \& Teknik. 2nd ed. Bandung: PT. Remaja Rosdakarya.

Ashar. 2016. "Kalimat Pertanyaan (Istifhâm) Dalam Surat Al-Kahfi (Analisis Pragmatik)." Universitas Negeri Semarang.

Chaer, Abdul. 2003. Psikolinguistik Kajian Teoretik. Jakarta: PT. Rineka Cipta.

Djajasudarma, Fatimah. 1999. Semantik Pemahaman Ilmu Makna. Bandung: Refika Aditama.

Fawwal, Azizah. 1992. Al-Mu'jam AlMufasshal. Beirut: Dar Al-Kutub AlIlmiyah.

Ghalayaini, Mustafa. 1984. Jami' Al-Duris Al-Arabiyah. Bairut: Al-Maktabah Al-Ashriyah.

Kholison, Mohammad. 2016. Semantik Bahasa Arab Tinjauan Historis Teoritik \& Aplikatif. Sidoarjo: CV. LISAN ARABI. 
Ma'sum, Ali. 2007. "Istifham Dalam

Alquran (Kajian Pragmatik Terhadap Penggunaan Kata Tanya Hamzah)."

Sekolah Pascasarjana Universitas

Islam Negeri (UIN) Syarif Hidayatullah Jakarta.

Nasution, Sahkholid. 2017. Pengantar Linguistik Bahasa Arab. 1st ed. edited by M. Kholison. Sidoarjo: CV. LISAN ARABI.

Nikmah, Khoirin. 2020. "Interrogative Sentence: A Contrastive Study of Arabic and Indonesian." Izdihar: Journal of Arabic Language Teaching, Linguistics, and Literature 2(3):183-200.

Nugrahani, Farida. 2014. Metode Penelitian Kualitatif Dalam
Penelitian Pendidikan Bahasa.

Surakarta.

Nurdiyanto, Ade Nurdiyanto. 2016. "Istifham Dalam Al-Qur'an: Studi Analisa Balaghah." El-Wasathiya: Jurnal Studi Agama 4(1):39-52.

Shihab, M. Qurais. 1994. Membumikan Al-Qur'an: Fungsi Dan Peran Wahyu Dalam Masyarakat. Bandung: Mizan Media Utama.

Shihab, M. Qurais. 2000. Wawasan AlQur'an. Bandung: Mizan Media Utama.

Zed, Mestika. 2004. Metode Penelitian Kepustakaan. Jakarta: Yayasan Obor Indonesia. 